\title{
Anatomical Variations and Clinical Correlations of Sacral Hiatus and Sacral Canal
}

\author{
${ }^{1}$ Ruchi Dhuria, ${ }^{2}$ Vandana Dave, ${ }^{3}$ Manish Ahuja, ${ }^{4}$ Shaifaly M Rustagi
}

\section{ABSTRACT}

Background: Sacral hiatus is nonfusion of the lamina of a fifth sacral vertebra in midline on the dorsal surface. The caudal epidural block is a common technique to introduce a needle into epidural space through sacral hiatus for surgical anesthesia and analgesia.

Aim: The objective was to study the morphological and morphometric variations of sacral hiatus and sacral canal in human sacra and to provide bony parameters for localization of sacral hiatus as an important landmark to access the epidural space for various clinical procedures successfully.

Materials and methods: The study was executed on 88 dry adult human sacra to scrutinize certain parameters of sacral hiatus and sacral canal including the shape of sacral hiatus, level of apex and base of sacral hiatus, length of sacral hiatus, anteroposterior distance at apex of sacral hiatus and intercornual distance at the base of hiatus.

Results: Inverted ' $U$ ' shape was most frequent (35.22\%) followed by inverted ' $V$ ' shape (29.24\%). The apex and base of sacral hiatus were commonly found at fourth (57.54\%) and fifth $(92.04 \%)$ sacral vertebral level respectively. The mean length of sacral hiatus was $28.17 \pm 16.62 \mathrm{~mm}$, the anteroposterior diameter at the apex of sacral hiatus was $6.66 \pm 2.71 \mathrm{~mm}$, and the intercornual distance at the base was $16.39 \pm 3.44 \mathrm{~mm}$.

Conclusion: Thorough knowledge of relevant anatomy and anatomical variations of sacral hiatus are imperative for clinicians for successful caudal epidural anesthesia.

Clinical significance: During caudal epidural anesthesia, incorrect needle placement in sacral hiatus may result in intraosseous drug toxicity and aspiration. Awareness about sacral hiatus and its variations may improve the understanding of disorders related to sacral nerve injuries.

Keywords: Caudal epidural block, Caudal epidural anesthesia, Sacrum, Sacral hiatus, Sacral canal.

How to cite this article: Dhuria R, Dave V, Ahuja M, Rustagi SM. Anatomical Variations and Clinical Correlations of Sacral Hiatus and Sacral Canal. J Med Acad, 2018;1(2):75-80.

Source of support: Nil

Conflict of interest: None

\section{${ }^{1,2}$ Tutor, ${ }^{3}$ Professor, ${ }^{4}$ Associate Professor \\ 1,2,4 Department of Anatomy, Army College of Medical Sciences, New Delhi, India \\ ${ }^{3}$ Department of Anatomy, Armed Forces Medical College, Pune, Maharashtra, India}

Corresponding Author: Vandana Dave, Tutor, Department of Anatomy, Army College of Medical Sciences, New Delhi, India, e-mail: daveveenu@gmail.com

\section{INTRODUCTION}

The sacrum is present between the two hip bones and forms the posterosuperior limit of the pelvic cavity. This large triangular bone is formed by the union of five sacral vertebrae and its transverse processes including their costal elements (S1-S5). Fusion of these primary cartilaginous joints starts at puberty from below upwards to form sacrum. The complete fusion of sacrum occurs between 23 years and 33 years of life. Sacrum articulates caudally with coccyx (sacrococcygeal joint) and cranially with fifth lumbar vertebra (lumbosacral joint). ${ }^{1}$ Vertebral foramina of five sacral vertebrae fuse posteriorly to form a sacral canal. It contains spinal meninges, epidural venous plexus, sacral and coccygeal nerve roots, filum terminale externum, cauda equina, and the fibrofatty tissue. The opening at the lower end of the sacral canal is called sacral hiatus, which is produced by the nonfusion of the lamina of the fifth sacral vertebra (S5). The developmental defect of nonfusion of the lamina of vertebral column or sacrum in the midline is known as spina bifida. Lumbar and sacral regions are the most common sites for complete agenesis of the sacrum. The filum terminale is present in sacral hiatus along with the fifth pair of sacral nerve and coccygeal nerve. ${ }^{2}$ The hiatus is enclosed posteriorly by skin, superficial fatty layer and sacrococcygeal membrane. ${ }^{3}$ The inferior articular processes of the fifth sacral vertebra project downwards to form the sacral cornu on both the sides of sacral hiatus. Sacral cornu is a chief landmark to move towards sacral hiatus during caudal epidural anesthesia as it lies about $0.5 \mathrm{~cm}$ above the tip of coccyx at the superior end of natal cleft. ${ }^{1}$

Caudal epidural anesthesia (CEA) is a common regional anesthesia to block sacral nerves through epidural space of sacral hiatus. ${ }^{4}$ Edward used the sacral hiatus to give caudal analgesia in labor pain for the first time. ${ }^{5}$ Knowledge of anatomical position, size, and shape of sacral hiatus have an important role in successful needle placement during caudal epidural block (CEB) in painless deliveries, orthopedic and perineal surgeries. ${ }^{6}$ Corticosteroid injections are also given through this route in sciatica. ${ }^{7}$ Contrast dyes are injected through sacral hiatus in epidural space in epidurography ${ }^{8}$ and spinal endoscopy. ${ }^{9}$

The sacral hiatus shows many variations in their shape and extent as per the literature review. Variation 
in the anatomical structure of sacral hiatus is a foremost cause of complications during the caudal epidural anesthesia such as a dural puncture. ${ }^{10,11}$ In $25 \%$ of cases, incorrect needle placement has been reported even with the experienced hand. ${ }^{12}$ Ultrasonography, fluoroscopy and other imaging technologies have been increasingly used to guide caudal epidural block with recent advancement. The objective of the current study was to find out the morphological variations of the sacral canal and sacral hiatus with its clinical correlations for successful anesthetic procedures and surgeries in various clinical settings.

\section{MATERIALS AND METHODS}

Eighty-eight completely ossified and undamaged, undetermined age and sex, dry sacral bones were obtained from Department of Anatomy, Army College of Medical Sciences, New Delhi, India. Anatomical measurements for these specimens of sacrum were taken by using aerospace digimatic vernier caliper (range 0-150 mm) accurate up to $0.01 \mathrm{~mm}$. We were inquisitive to verify the significance of anatomical variations of sacrum related to their shape and extent of sacral hiatus and sacral canal. Each sacrum was studied to evaluate the shape of sacral hiatus, level of apex and base of sacral hiatus, length of sacral hiatus from apex to midpoint of the base, anteroposterior diameter at the apex of sacral hiatus and intercornual distance at the base of sacral hiatus. Observations were noted and analyzed by using Microsoft Excel and Statistical Package for Social Sciences (SPSS), version 22 (SPSS-22, IBM, Chicago, IL, USA). Mean, standard deviation and range of collected data were then calculated.

\section{RESULTS}

Morphological and morphometric measurements of sacrum were observed for sacral hiatus, and the sacral canal is given in Tables 1 to 6 . Out of 88 sacra, three cases were showing complete agenesis (3.4\%) (Fig. 1), and seven sacra were showing partial agenesis (7.95\%) (Fig. 2) of dorsal wall of the sacral canal. Sacral hiatus was absent in eight sacra because of the merging of the laminae of fifth sacral vertebrae (length of sacral hiatus $\leq 6 \mathrm{~mm}$ ) (Fig. 3).

Table 1: Distribution of different shapes of sacral hiatus

\begin{tabular}{llll}
\hline S. & & Number of & \\
no. & Shape of sacral hiatus & sacra $(n=88)$ & Percentage \\
\hline 1. & Inverted 'U' shaped & 31 & 35.22 \\
2. & Inverted 'V' shaped & 26 & 29.54 \\
3. & Irregular shaped & 13 & 14.77 \\
4. & Absent sacral hiatus & 8 & 9.09 \\
5. & Partial dorsal wall & 7 & 7.95 \\
& agenesis & & 3.4 \\
\hline 6. & Complete dorsal wall & 3 & \\
\hline
\end{tabular}

Table 2: Vertebral level of apex of sacral hiatus

\begin{tabular}{llll}
\hline $\begin{array}{l}\text { S. } \\
\text { no. }\end{array}$ & Level of apex of sacral & $\begin{array}{l}\text { Number of } \\
\text { sacra }(n=88)\end{array}$ & Percentage \\
\hline 1. & 5th sacral vertebra & 8 & 9.09 \\
2. & 4th sacral vertebra & 51 & 57.95 \\
3. & 3rd sacral vertebra & 19 & 21.59 \\
4. & 2nd sacral vertebra & 5 & 5.68 \\
5. & 1st sacral vertebra & 2 & 2.27 \\
6. & Complete spina bifida & 3 & 3.40 \\
& without apex & & \\
\hline
\end{tabular}

Table 3: Vertebral level of base of sacral hiatus

\begin{tabular}{llll}
\hline S. & Level of base of & $\begin{array}{l}\text { Number of sacra } \\
(n=88)\end{array}$ & Percentage \\
no. & sacral hiatus & 0 & 0 \\
1. & 4th sacral vertebra & 01 & 92.04 \\
2. & 5th sacral vertebra & 81 & 7.95 \\
3. & Coccyx & 7 & \\
\hline
\end{tabular}

Table 4: Length of sacral hiatus from apex to midpoint of base of sacral hiatus

\begin{tabular}{|c|c|c|c|}
\hline $\begin{array}{l}\text { S. } \\
\text { no. }\end{array}$ & $\begin{array}{l}\text { Length of sacral } \\
\text { hiatus from apex to } \\
\text { midpoint of base }(\mathrm{mm})\end{array}$ & $\begin{array}{l}\text { Number of } \\
\text { sacra }(n=88)\end{array}$ & Percentage \\
\hline 1. & $0-10$ & 9 & 10.22 \\
\hline 2. & $10.1-20$ & 14 & 15.9 \\
\hline 3. & $20.1-30$ & 33 & 37.5 \\
\hline 4. & $30.1-40$ & 22 & 25 \\
\hline 5. & $40.1-50$ & 2 & 2.27 \\
\hline 6. & 50.1 and above & 5 & 5.68 \\
\hline 7. & $\begin{array}{l}\text { Complete dorsal wall } \\
\text { agenesis }\end{array}$ & 3 & 3.40 \\
\hline
\end{tabular}

Table 5: Intercornual distance at base of sacral hiatus

\begin{tabular}{|c|c|c|c|}
\hline $\begin{array}{l}\text { S. } \\
\text { no. }\end{array}$ & $\begin{array}{l}\text { Intercornual } \\
\text { distance at base of } \\
\text { sacral hiatus ( } \mathrm{mm})\end{array}$ & $\begin{array}{l}\text { Number of sacra } \\
(n=88)\end{array}$ & Percentage \\
\hline 1. & $0-5$ & 0 & 0 \\
\hline 2. & $5.1-10$ & 4 & 4.54 \\
\hline 3. & $10.1-15$ & 27 & 30.68 \\
\hline 4. & $15.1-20$ & 48 & 54.54 \\
\hline 5. & $20.1-25$ & 9 & 10.22 \\
\hline
\end{tabular}

Table 6: Anteroposterior diameter at the apex of sacral hiatus

\begin{tabular}{llll}
\hline \multicolumn{3}{l}{ Anteroposterior } & \\
S. & $\begin{array}{l}\text { diameter at the apex } \\
\text { of sacral hiatus }(\mathrm{mm})\end{array}$ & $\begin{array}{l}\text { Number of } \\
\text { sacra }(n=88)\end{array}$ & Percentage \\
\hline 1. & $0-3$ & 5 & 5.68 \\
2. & $3.1-6$ & 42 & 47.72 \\
3. & $6.1-9$ & 25 & 28.4 \\
4. & $9.1-12$ & 9 & 10.22 \\
5. & $>12$ & 4 & 4.54 \\
6. & Complete dorsal wall & 3 & 3.40 \\
& agenesis & & \\
\hline
\end{tabular}

Sacral hiatus of inverted ' $U$ ' shape (Fig. 4) was the most frequent shape seen in $35.22 \%$ cases followed by Inverted ' $V$ ' shape (29.54\%) (Fig. 5). $14.77 \%$ of cases were found with the irregular shape of sacral hiatus (Fig. 6 


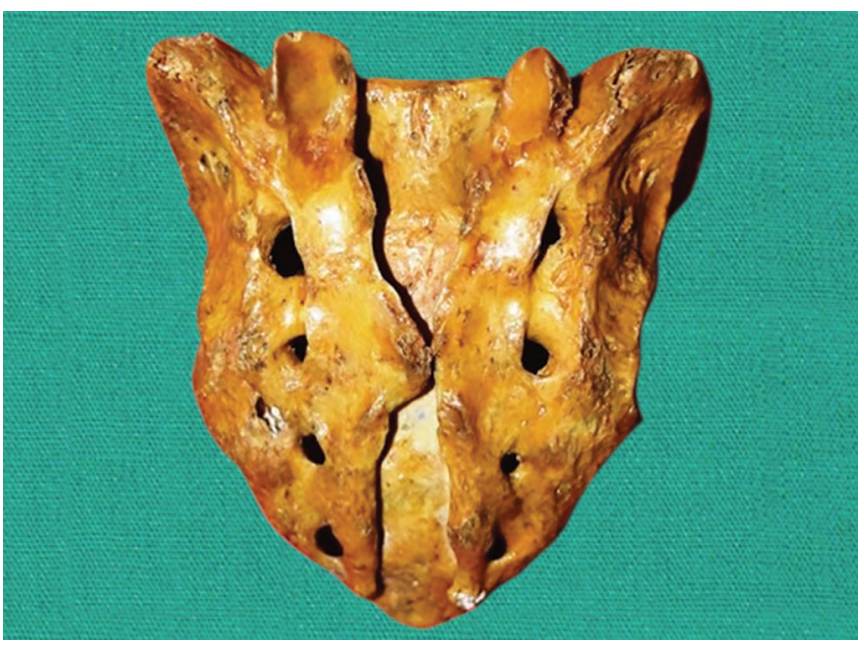

Fig. 1: Complete dorsal wall agenesis of the sacrum

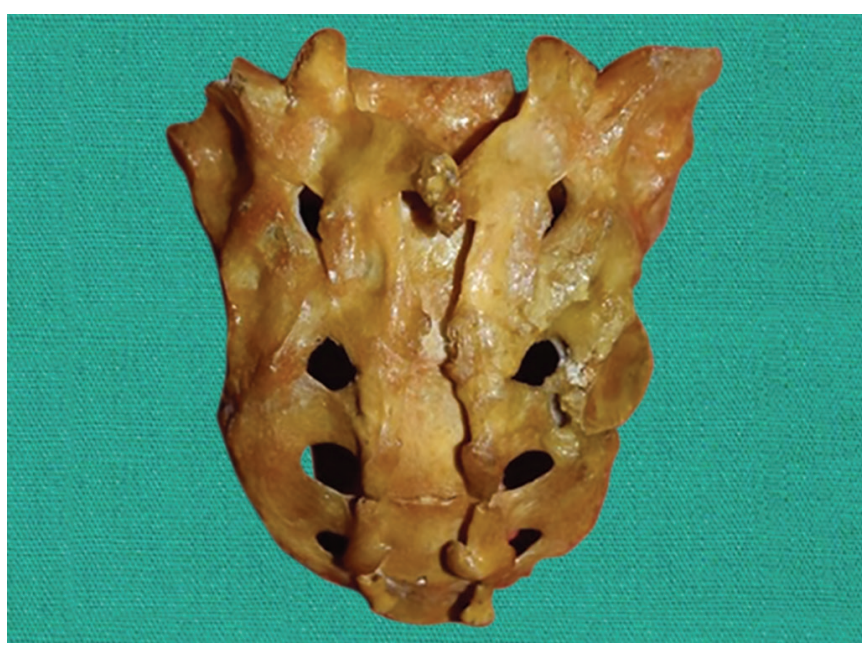

Fig. 2: Incomplete dorsal wall agenesis of the sacrum

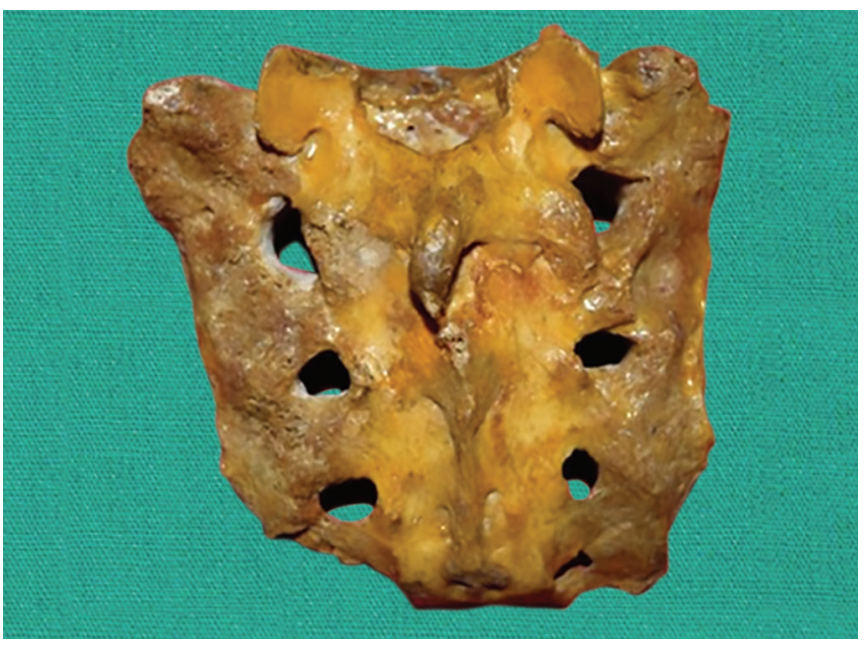

Fig. 3: Absent sacral hiatus with the fused lamina

and Table 1). The most usual position for the apex of sacral hiatus was fourth sacral vertebra (57.45\%) (Table 2), while the base was at fifth sacral vertebra $(92.04 \%)$ (Table 3). The mean length of the sacral hiatus was 28.17 $\pm 16.62 \mathrm{~mm}$ (range $2-88 \mathrm{~mm}$ ) (Table 4$)$. The mean \pm SD for

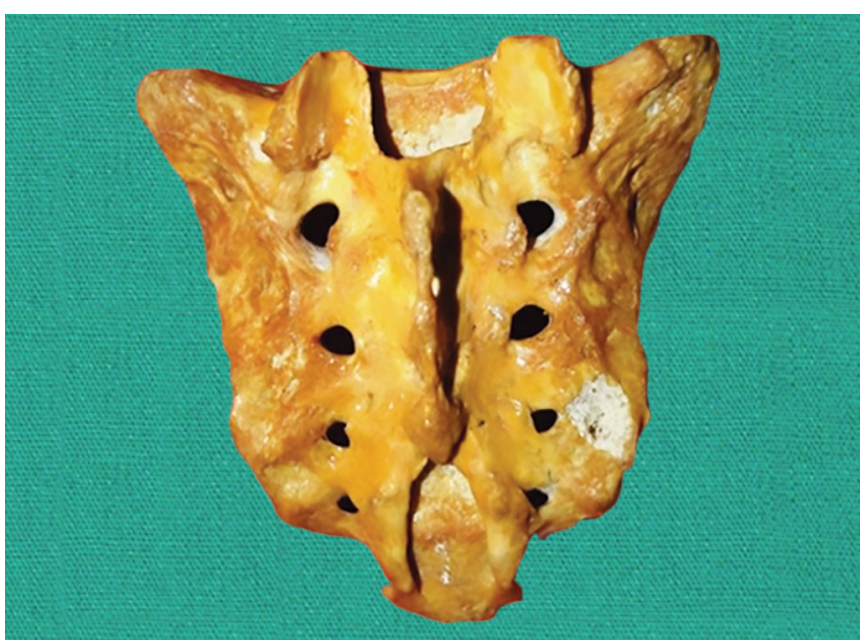

Fig. 4: Inverted 'U' shaped sacral hiatus

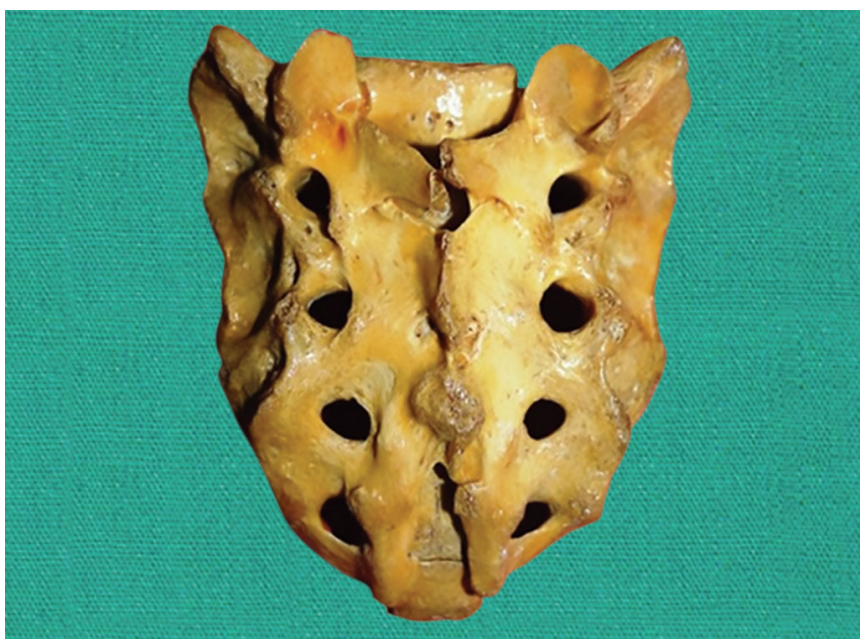

Fig. 5: Inverted 'V' shaped sacral hiatus

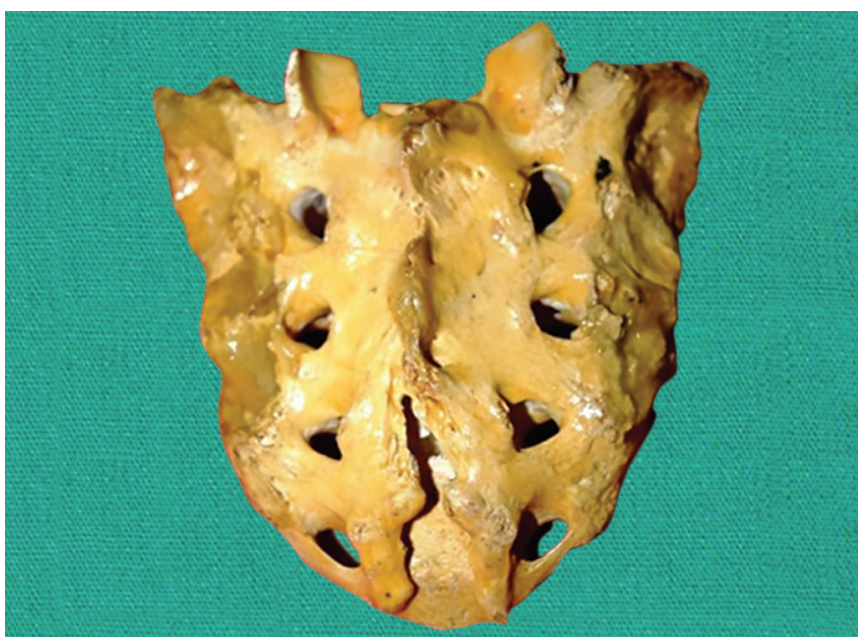

Fig. 6: Irregular shaped sacral hiatus

intercornual transverse diameter at fifth sacral vertebra was calculated $16.39 \pm 3.44 \mathrm{~mm}$ (range $8-25 \mathrm{~mm}$ ) (Table 5). The mean \pm SD for anteroposterior diameter was $6.66 \pm$ $2.71 \mathrm{~mm}$ (range $1.5-15 \mathrm{~mm}$ ) at the apex of sacral hiatus (Table 6). 


\section{DISCUSSION}

Sacral hiatus is a significant bony landmark for the successful caudal epidural block. Detection of caudal epidural space is not achievable always for even experienced clinicians because of the influence of anatomical variations of the sacrum. Our measurements will lead to an increase in the success rate of the caudal epidural block by easy detection of sacral hiatus.

\section{Shape of Sacral Hiatus}

According to standring $\mathrm{S}^{2}$, the sacral hiatus is usually triangular, or inverted ' $U$ ' shaped structure. Following studies by Nagar, ${ }^{13}$ Seema ${ }_{1}^{14}$ Sinha, ${ }_{1}^{15}$ Nadeem, ${ }_{1}^{16}$ Ukoha, ${ }_{1}^{17}$ Akhtar ${ }^{18}$ observed that inverted ' $U$ ' shape is the most frequent shape of sacral hiatus followed by inverted ' $\mathrm{V}$ ' shape as observed in the current study. Whereas, $\mathrm{Kumar}^{19}$ and Nasr' observed that inverted ' $V$ ' shape is more common than inverted ' $U$ ' shape. In our study, the sacral hiatus was absent in $9.09 \%$ cases probably because of bony overgrowth or fused lamina of the sacrum (Table 7). The absent sacral hiatus may cause needle breakage or obstruction during needle insertion for caudal epidural anesthesia. The precise knowledge of sacral hiatus will increase the success rate of caudal epidural block. Tsui ${ }^{20}$ observed a $25 \%$ failure rate in the caudal epidural block and reported anatomical variations in sacral hiatus as the commonest cause of failure.

\section{Apex of Sacral Hiatus}

Awareness about the position of the apex of sacral hiatus is imperative as it lies near to the lower edge of the dural sac. Higher apex leads to additional chances of dural sac puncture at the time of caudal epidural anesthesia. Thus, in cases of the higher apex, more precautions are required while deciding the length of the spinal needle for CEA procedure. Previous studies by Nagar, ${ }^{13}$ Seema, ${ }^{14}$ Sinha, ${ }^{15}$ Ukoha, ${ }^{17}$ Chhabra, ${ }^{21}$ and Akhtar ${ }^{18}$ reported maximum cases of the apex of sacral hiatus at fourth sacral vertebra (S4). Nadeem ${ }^{16}$ reported the most common site for the apex of sacral hiatus at third sacral vertebra (S3). In our finding, we also found maximum sacra $(57.95 \%)$ with the apex of sacral hiatus at third sacral vertebral level (S3) (Table 8).

\section{Base of Sacral Hiatus}

The location of the base of sacral hiatus ranges from fourth sacral vertebra to the coccyx. In our study, the most ordinary location for a base of sacral hiatus was the fifth sacral vertebrae $(92.04 \%)$ (Table 3). This finding is in agreement with Nagar, ${ }^{13}$ Seema ${ }_{1}^{14}$ Sinha, ${ }_{1}^{15}$ Ukoha,${ }_{1}^{17}$ Chhabra, ${ }^{21}$ Nadeem, ${ }_{16}^{16}$ and Akhtar. ${ }^{18}$ In $7.95 \%$ of cases, the base of sacral hiatus was situated at coccygeal level. Akhtar ${ }^{18}$ also stated that the base of sacral hiatus at the level of coccyx is slightly narrower in comparison to a sacral level which leads to coccygeal ankylosis. Coincidently, we didn't find any base of sacral hiatus at fourth sacral vertebra (S4) in our study (Table 9).

\section{Length of Sacral Hiatus}

The length of sacral hiatus ranged from 2 to $88 \mathrm{~mm}$ with a mean of $28.17 \pm 16.62 \mathrm{~mm}$ as per our observation. We found $55 \%$ of the sacra in $20.01-40 \mathrm{~mm}$ range which is on the higher side in comparison to the other studies. Chhabra ${ }^{21}$ reported the mean length of sacral hiatus 25.05 $\pm 10.96 \mathrm{~mm}$ which is nearer to our observation. Akhtar ${ }^{18}$ reported the most common range for the length of sacral hiatus between $10.01 \mathrm{~mm}$ and $30 \mathrm{~mm}$ in $58 \%$ cases with mean value $26.92 \pm 12.91 \mathrm{~mm}$. Nagar ${ }^{13}$ also observed maximum cases $(65.08 \%)$ belongs to $11-30 \mathrm{~mm}$ length of sacral hiatus. Seema ${ }^{14}$ and Nadeem ${ }^{16}$ also noticed the mean length between $11 \mathrm{~mm}$ and $30 \mathrm{~mm}$ for sacral hiatus in almost two-thirds of cases.

\section{Intercornual Distance at the Base of Sacral Hiatus/Transverse Width of Sacral Hiatus at the Base}

The current study shows that intercornual distance at the base of sacral hiatus ranged from 8 to $25 \mathrm{~mm}$ with the mean \pm SD of $16.39 \pm 3.44 \mathrm{~mm}$. In $54.54 \%$ cases, the transverse width of sacral hiatus was calculated between 15.1 $\mathrm{mm}$ and $20 \mathrm{~mm}$ followed by $30.68 \%$ between $10.1 \mathrm{~mm}$ and $15 \mathrm{~mm}$. Kumar, ${ }_{1}^{19}$ Nagar, $_{1}^{13}$ Sinha, ${ }_{1}^{15}$ and Akhtar $^{18}$ found intercornual distance at the base of sacral hiatus between $10.1 \mathrm{~mm}$ and $15 \mathrm{~mm}$ in 52\%, 54\%, 41.93\%, and $48.39 \%$ cases respectively, whereas, we found maximum cases $(54.54 \%)$ in $15.1-20 \mathrm{~mm}$ range. Nadeem ${ }^{16}$ also

Table 7: Comparison between shapes of sacral hiatus by different workers

\begin{tabular}{|c|c|c|c|c|c|c|c|c|c|}
\hline $\begin{array}{l}\text { Shape of } \\
\text { sacral hiatus }\end{array}$ & Kumar V & Seema & Sinha $M B$ & Nadeem G & Ukoha U & Akhtar J & Nagar SK & Nasr AY & $\begin{array}{l}\text { Present } \\
\text { study }\end{array}$ \\
\hline $\begin{array}{l}\text { inverted 'U' } \\
\text { shape }\end{array}$ & $29.70 \%$ & $42.95 \%$ & $35.93 \%$ & $56 \%$ & $48.2 \%$ & $44.36 \%$ & $41.50 \%$ & $31.33 \%$ & $35.22 \%$ \\
\hline $\begin{array}{l}\text { inverted 'V' } \\
\text { shape }\end{array}$ & $46.53 \%$ & $27.51 \%$ & $17.18 \%$ & $14 \%$ & $34.9 \%$ & $35.48 \%$ & $27 \%$ & $38.66 \%$ & $29.54 \%$ \\
\hline Irregular & - & $16.10 \%$ & $15.62 \%$ & $16 \%$ & $4.8 \%$ & $8.87 \%$ & $14.10 \%$ & $15.33 \%$ & $14.77 \%$ \\
\hline Absent & $0.99 \%$ & $2.51 \%$ & $3.12 \%$ & - & $1.20 \%$ & $2.42 \%$ & $0.70 \%$ & - & $9.09 \%$ \\
\hline
\end{tabular}


Table 8: Comparison of level of apex of sacral hiatus by different workers

\begin{tabular}{llllll}
\hline & \multicolumn{5}{c}{ Level of apex } \\
\cline { 2 - 6 } Authors Name & S1 & S2 & S3 & S4 & S5 \\
\hline Nagar SK & - & $3.4 \%$ & $37.3 \%$ & $55.9 \%$ & $3.40 \%$ \\
Seema et al. & - & $4.03 \%$ & $53.57 \%$ & $56.37 \%$ & $4.03 \%$ \\
Sinha M B & - & - & $25 \%$ & $70.86 \%$ & $6.45 \%$ \\
Ukoha U & - & $2.4 \%$ & $20.5 \%$ & $69.9 \%$ & $4.8 \%$ \\
Chhabra N & - & $6.67 \%$ & $33.33 \%$ & $60 \%$ & - \\
Nadeem G & - & $2 \%$ & $62 \%$ & $34 \%$ & $2 \%$ \\
Akhtar J & - & $2.42 \%$ & $20.97 \%$ & $71.77 \%$ & $4.84 \%$ \\
Present study & $2.27 \%$ & $9.09 \%$ & $57.95 \%$ & $21.59 \%$ & $5.68 \%$ \\
\hline
\end{tabular}

Table 9: Comparison of level of base of sacral hiatus by different workers

\begin{tabular}{llll}
\hline Authors Name & \multicolumn{3}{l}{ Level of base of sacral hiatus } \\
\hline & S4 & S5 & Coccyx \\
\hline Nagar SK & $11.10 \%$ & $72.60 \%$ & $16.30 \%$ \\
Seema & $13.42 \%$ & $70.46 \%$ & $16.10 \%$ \\
Sinha M B & $6.45 \%$ & $88.71 \%$ & $4.83 \%$ \\
Ukoha U & $2.4 \%$ & $88 \%$ & $7.2 \%$ \\
Chhabra N & $20 \%$ & $63.33 \%$ & $16.67 \%$ \\
Nadeem G & $24 \%$ & $62 \%$ & $14 \%$ \\
Akhtar J & $12.10 \%$ & $79.84 \%$ & $8.06 \%$ \\
Present study & - & $92.04 \%$ & $7.95 \%$ \\
\hline
\end{tabular}

observed $52 \%$ of cases with more than $15 \mathrm{~mm}$ width. Mustafa $^{22}$ reported the mean transverse width of the base of sacral hiatus was $1.7 \pm 0.26 \mathrm{~cm}$ in Egyptian sacra which is comparable to our study.

\section{Anteroposterior Diameter of Sacral Hiatus at its Apex}

Anteroposterior diameter of the sacral canal is imperative for $\mathrm{CEB}$ procedures because it gives adequate space to enter the needle in the epidural space of sacrum. The discrepancy in the diameter of the sacral canal would result in deposition of anesthetic drugs subcutaneously. The observations of our work reveal the anteroposterior diameter at the apex of sacral hiatus varied from 1.5 to $15 \mathrm{~mm}$ with a mean of $6.66 \pm 2.71 \mathrm{~mm}$. Nagar, ${ }^{13}$ Seema, ${ }^{14}$ Nadeem, ${ }^{16}$ Ukoha, ${ }_{17}$ Chhabra, ${ }^{21}$ and Akhtar ${ }^{18}$ reported anteroposterior diameter at the apex of sacral hiatus were $4.88 \mathrm{~mm}, 4.7 \mathrm{~mm}, 5.53 \mathrm{~mm}, 5.52 \pm 1.89 \mathrm{~mm}, 6.3 \pm$ $1.39 \mathrm{~mm}, 5.39 \pm 1.96 \mathrm{~mm}$, respectively. Our result is close to the observation of $\mathrm{Chhabra}^{21}$ for the anteroposterior diameter of the apex of sacral hiatus.

\section{CONCLUSION}

Ultrasound-guided needle placement for the caudal epidural block is recommended for overall success. Fluoroscopy is considered as a gold standard technique for placing needles correctly in the sacral hiatus still it is not always possible due to personal availability, time and cost consent. Therefore, an acquaintance of anatomical varia- tions of the sacral canal and sacral hiatus is an essential landmark for clinicians to facilitate the procedure of caudal epidural anesthesia to improve its success rate.

\section{Clinical Significance}

Incomplete development of dorsal neural arches of sacrum may result as incomplete neurogenesis of sacral nerves. This could lead to partial or complete incontinence of urinary bladder and bowel disorders. Usually, patients with dorsal wall agenesis of the sacrum are linked with such conditions like posterior disk herniation, backache, enuresis, bowel disorders and weakness of lower limbs. ${ }^{23}$ Variations in the development of sacral hiatus can decrease the region for attachment of extensor muscles at the dorsal surface of sacrum resulting in painful condition..$^{24}$ Anatomical and developmental variations of the sacral canal and sacral hiatus make sacrum more liable to fracture, difficulty while performings internal screw fixation and other clinical complications.

Incorrect needle placement during caudal anesthesia has been linked with intraosseous drug toxicity, and aspiration. ${ }^{25}$ Knowledge of anatomical variations might increase the success rate of caudal epidural anesthesia. Moreover, when the clinicians notice an abnormal sacral hiatus, he/she should opt for a lumbar epidural block or an alternative route for anesthesia to avoid the soft tissue injury and the toxicity of local anesthetics.

\section{REFERENCES}

1. Nasr AY, Ali YH, Elsawy NA. The Sacral Hiatus: An Anatomical Study on both Cadaveric and Dry Bones. Trans Clin Bio 2014;2(1):4-12.

2. Standring S, editor. Gray's Anatomy - The Anatomical Basis of Clinical Practice. 40th ed. London: Churchill Livingstone Elsevier; 2008. p. 724-728.

3. Sekiguchi M, Yabuki S, Satoh K, Kikuchi S. An anatomic study of the sacral hiatus: A basis for successful caudal epidural block. Clin J Pain 2004;20:51-54.

4. Chen PC, Tang SF, Hsu TC, Tsai WC, Liu HP, Chen MJ, Date E, Lew HI. Ultrasound guidance in caudal epidural needle placement. Anesthesiology 2004;101:181-184.

5. Edwards WB, Hingson R. Continuous caudal anaesthesia in obstetrics. Am J Surg 1942;57:459-464.

6. Shinde AA, Manvikar PR, Bharambe VK. Morphometric study of sacral hiatus and its significance in caudal epidural anesthesia. Sahel Med J 2015;18:134-138.

7. Czarski Z. Treatment of sciatica with hydrocortisone and novocaine injection into the sacral hiatus. Przegl Lek. 1965, 21(7):511-513.

8. Devulder J, Bogaert L, Castille F, Moerman A, Rolly G. Relevance of epidurography and epiduralysis in chronic failed back surgery patients. Clin J Pain. 1995;11(2):147150.

9. Helm Sznd, Gross JD, Varley KG. Mini surgical approach for spinal endoscopy in the presence of stenosis of the sacral hiatus. Pain Physician. 2004;7(3):323-325. 
10. Kim DW, Lee SJ , Choi EG, Lee PB, Jo YH, Nahm FS. Morphologic Diversities of Sacral Canal in Children; ThreeDimensional Computed Tomographic Study. Korean J Pain 2014;27(3):253-259.

11. Saha D, Bhattacharya S, Uzzaman A, MazumdarS, Mazumdar A. Morphometric study of variations of sacral hiatus among West Bengal population and clinical implications. Italian Journal of Anatomy and Embryology. 2016, p. 165-171,

12. Amin R, Shahdad S, Ali U, Nazir M, Aslam B. Study of variations of sacral hiatus. Indian Journal of Research. 2018;7(4): 82-84.

13. Nagar SK. A study of sacral hiatus in dry human sacra. J Anat Soc India 2004;3(2):18-21.

14. Seema, Singh M, Mahajan A. An anatomical study of variations of sacral hiatus in sacra of north indian origin and its clinical significance. Int J Morphol. 2013;31(1):110-114.

15. Sinha MB, Rathore M, Sinha HR. A study of variation of sacral hiatus in dry bone in central Indian region. Int J of Healthcare and Biomedical Research. 2014;2(4):46-52.

16. Nadeem G. Importance of knowing the level of sacral hiatus for caudal epidural anaesthesia. Int J Morphol. 2014;31(1): 9-13.

17. Ukoha UU, Okafor JI, Anyabolu AE, Ndukwe GU, Eteudo AN, Okwudiba NJ. Morphometric study of the sacral hiatus in nigerian dry human sacral bones. Int J Med Res Health Sci. 2014;3(1):115-119.
18. Akhtar J, Fatima N, Ritu, Kumar A, Kumar V. A Morphometric study of sacral hiatus and its importance in caudal epidural anaesthesia. Int J of Anatomy, Radiology and Surgery. 2016;5(1):6-11.

19. Kumar V, Pandey SN, Bajpai RN, Jain PN, Longia GS. Morphometrical study of sacral hiatus. J Anat Soc India. 1992;41(1): 7-13.

20. Tsui BC, Tarkkila P, Gupta S, Kearney R. Confirmation of caudal needle placement using nerve stimulation. Anesthesiology 1999;91:374-378.

21. Chhabra N. An anatomical study of size and position of sacral hiatus; its importance in caudal epidural block. Int J of Health Sciences and Research. 2014;4(12):189-196.

22. Mustafa MS, Mahmoud OM, Raouf HH, Atef HM. Morphometric study of sacral hiatus in adult human Egyptian sacra: their significance in caudal epidural anaesthesia. Saudi J Anaesthe. 2012;6:350-357.

23. Galloway NT, Tanish J. Minor defects of the sacrum and neurogenic bladder dysfunction. Br J Urol 1985;57:154-155.

24. Brailsford JF. Deformaties of lumbosacral region of spine. $\mathrm{Br}$ J Surg. 1929;16(64):562-627.

25. Ogoke BA. Caudal e[idural steroid injections. Pain Physician 2000;3:305-312. 